Research Article

\title{
Development of an Arduino Based Electric Cooker Timer System
}

\author{
Ajibola O. Oyedeji ${ }^{1}$, Abiola P. Oni ${ }^{1}$, Frank Onaifo ${ }^{2}$, Peter O. Alao ${ }^{2}$ \\ ${ }^{1}$ Department of Computer Engineering, Olabisi Onabanjo University, Ago-Iwoye, Nigeria \\ ${ }^{2}$ Department of Electrical and Electronics Engineering, Olabisi Onabanjo University, Nigeria
}

\section{ARTICLE INFORMATION}

Received: February $9^{\text {th }}, 2020$

Revised: March $7^{\text {th }}, 2020$

Available online: March $30^{\text {th }}, 2020$

\section{KEYWORDS}

Microcontroller, Timer, LCD display, Power supply

\section{CORRESPONDENCE}

Phone: $+234(905) 6728637$

E-mail: oyedeji.ajibola@oouagoiwoye.edu.ng

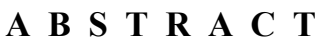

\begin{abstract}
The emerging trend in the world of semiconductor integration has brought about so many opportunities in the area of microcontrollers. This paper deals with the design and implementation of a microcontroller-based timer for home appliances using an Arduino microcontroller. This system is developed for the users to pre determine the time of operation of any home appliances using the electric cooker for implementation. The system is majorly comprised of the power supply unit, microcontroller unit, timer circuits and LCD display. The user can set any of the time given in the timer switch using keypad. The settings are stored in the microcontroller and the details are displayed in the LCD display. The appliance is controlled to run for the particular period set by the timer switch. The timer switch automatically makes the appliance off once the period is over. This system has been designed to be efficient, reliable and reduce energy wastage.
\end{abstract}

\section{INTRODUCTION}

Advancement in technology has made all aspects of life simpler and easier thereby making automated systems more preferred to manual systems [1]. Automatic timer systems are designed to control and properly manage the time. Timers used to schedule events according to a pre-set time value are integral parts of diverse real-time embedded systems. They find applications in the control of sequential functions of industrial machinery at varying time intervals, in the laboratory to power instruments for a specific time and perform processes for a specific duration or even home appliances [2].

Due to continuous advancement in technology, the society's lifestyle changes in order to adapt to new trends as it make it extremely easier and faster to get things done. Cooking methods have greatly improved over the years from the crude method of using firewood to electrical means (electric cookers). The use of electric cookers provides a safe way of cooking but doesn't eliminate the risk associated with it. Occasionally, incompetent use of the device can result in the initially stated accident.

To further enhance safety in the usage of electric cookers, this project designs an Arduino based timer for electric cooker. This cooker is equipped with a system that allows the user to assign specific period of operation and automatically shuts off after the set amount of time. The cooker is also equipped with other actuators such as buzzer, which gives an audio notification at set times to notify the user of the timer's progress.

The idea of automation can be employed in various real life situations that can help to further improve efficiency of devices or appliances, as it provides a medium where the user can specify a method of operation for appliances or device with ease and little or no addition effort. It can be applied in various areas such as transportation vehicles: auto pilot, GPS navigator, consumer products, security systems etc [3] [4]. Some common applications include the automatic lawn watering systems which uses the preprogrammed code of a microcontroller to power the lawn watering device to turn on and function for certain period of time at specific intervals daily.

A microcontroller based light dependent alarm system was designed and implemented using Arduino microcontroller to monitor the presence or absence of light, and thereafter activates a sound alarm signal to the buzzer [5]. In [6], a microcontroller based universal On-Off timer for home appliances was designed, developed and implemented for the users to control the operation of any home appliances using two different types of relays for high powered and low powered appliances. 
In [7], a smart home automation system was designed and implemented using a low-cost Arduino Mega 2560 microcontroller. Upon implementation, a highly scalable, lowcost home automation system capable of integrating home appliances, smoke and gas leakage detection was successfully delivered.

\section{THE MICROCONTROLLER BASED TIMER SYSTEM DESIGN}

The purpose of this project is to design and implement a timer system using an Arduino microcontroller to efficiently control the usage of the electric cooker by assigning a time limit to its function in order to reduce energy and other resource wastage. To achieve this a timer system is attached to the cooker to serve as its power switch at the same time a safety measure, which means the cooker is entirely time reliant and a specific time should be entered before it can be turned on. Figure 1 below shows the block diagram of the system with the major units or blocks shown.

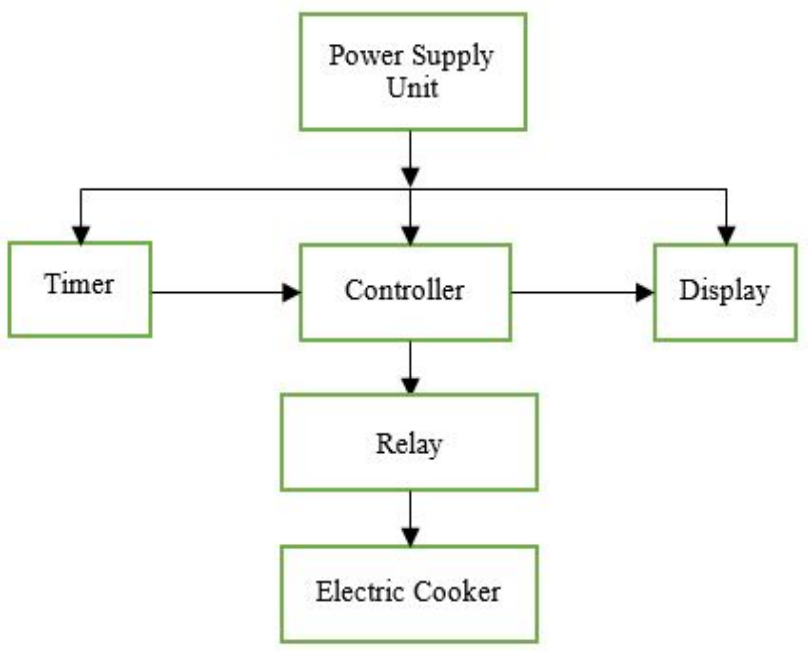

Figure 1. Block Diagram of the Microcontroller Based Timer System

The timer system consists of a push buttons on which the user can enter the desired time and all required automation processed will be handled by a microcontroller (Arduino UNO) on which every other actuators are connected. The microcontroller serves as the brain of the system which tells other connected components when and how to function [8]. The relay module toggles and switches the electrical appliance on/off depending on the signal received from the controller. The power supply unit powers the whole system while the LCD display is used to output the state of the system.

\section{The Hardware Design}

A proper circuit design and simulation should be implemented to achieve the desired project. Fig. 2 shows the circuit diagram which serves as a guide to design a proper circuit for the timer switch in which the Arduino UNO controls the other components to perform the desired operation in accordance to the user preference. Proteus simulation software is used to virtually connect the essential components together to determine how the circuit will be connected on a Vero board. The specification of the Arduino Uno is shown in Table1.
Table 1. Technical Specification of the Arduino Uno

\begin{tabular}{cc}
\hline Parameter & Value \\
\hline Operating Voltage & 5 Volts \\
\hline Input Voltage & $7-20$ Volts \\
\hline Digital I/O Pins & 14 (6 for PWM output $)$ \\
\hline Analog Input Pins & 6 \\
\hline DC Current per I/O Pin & $20 \mathrm{~mA}$ \\
\hline DC Current for 3.3V Pin & $50 \mathrm{~mA}$ \\
\hline Flash Memory & $32 \mathrm{~KB}$ \\
\hline SRAM & $2 \mathrm{~KB}$ \\
\hline EEPROM & $1 \mathrm{~KB}$ \\
\hline Clock Speed & $16 \mathrm{MHZ}$ \\
\hline
\end{tabular}

The system consist of a microcontroller (Arduino UNO) which takes in all necessary data, processes it and assigns required command to other function components in real time. Push buttons are used to set time which is displayed on the $16 \times 2 \mathrm{LCD}$ modules in a countdown format to show the user how much time is left. A single channel relay module connects the system with the cooker and is used to turn on or off the cooker according to the data received from the microcontroller.

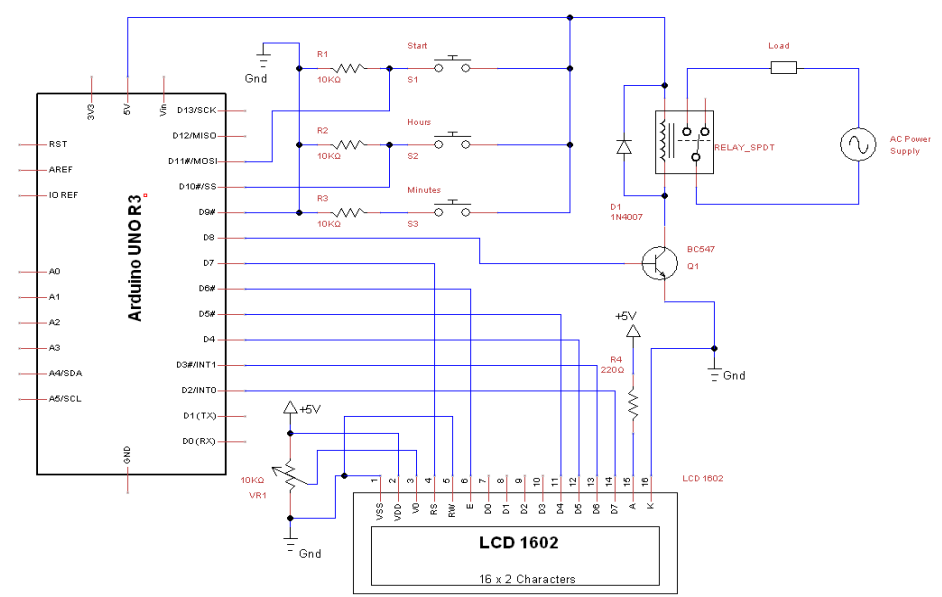

Figure 2. Circuit Diagram of the Timer System

The Arduino UNO microcontroller requires a $5 \mathrm{~V}$ to power up in which a higher or lesser volt will damage the circuit or will not power it. This system uses just one power source to power the components and the electric cooker which is about $220 \mathrm{~V}-240 \mathrm{~V}$ which is higher than the required voltage for the microcontroller. To prevent damage, a step down transformer is used to step down the voltage to the required voltage for the microcontroller which in turn powers the attached components.

Every component comes with a specifications data sheet, microcontroller for instance has many manufacturing brands and specifications. The hardware consists of buttons, LCD module, microcontroller and relays and its appropriate power supply. All components are connected to the microcontroller which is powered with a voltage of $5 \mathrm{~V}$. The microcontroller can take up to $9 \mathrm{~V}$ charge and anything higher will damage the circuit board. As a result of the all attached components should run on voltage lower or equal to $5 \mathrm{~V}$ otherwise an external power source is required. 


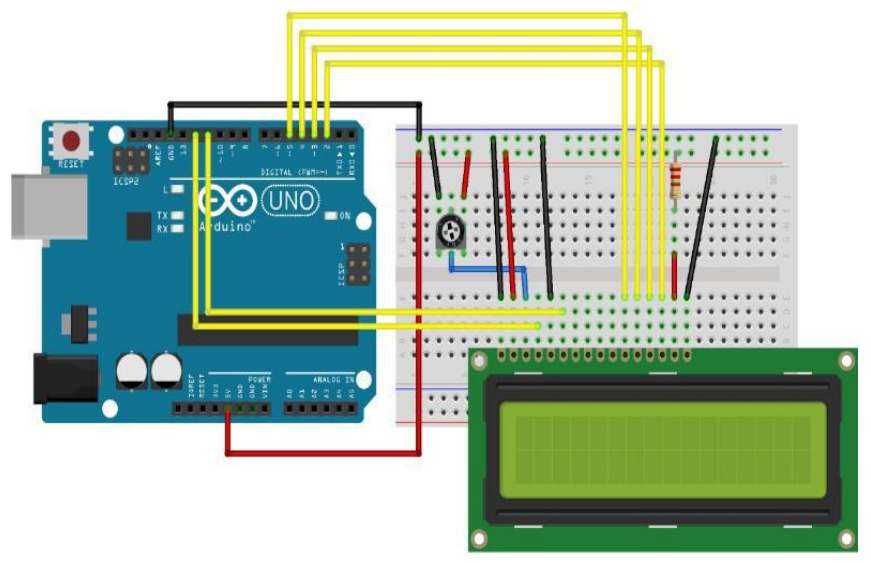

Figure 3. Connection for LCD Module

The LCD module is connected to the Arduino pin 2, 3, 4,5,11 and 12. It is also properly connected to the Arduino 5V and GND which are the positive and negative respectively. A 10k ohms resistor is use to regulate the amount of current it receives and also a potentiometer to adjust the brightness of the backlight as shown in Figure 3. Figure 4 shows the overall system on the breadboard.

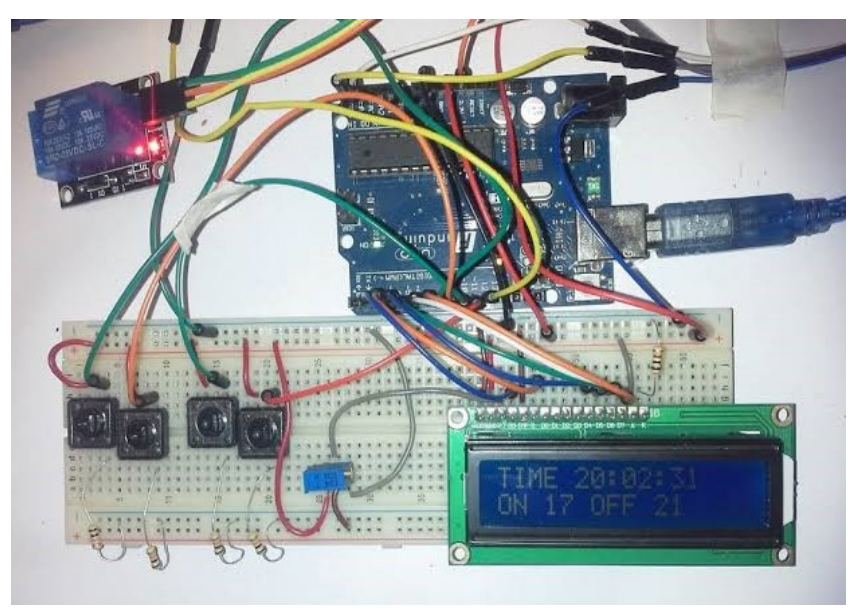

Figure 4. Breadboard Connection

\section{The Software Design}

The microcontroller on the board is programmed using the Arduino $\mathrm{C}$ programming language and the platform makes use of a software called Arduino Integrated Development Environment (IDE) which is a programming environment with debugging ability to debug programming errors. The process flowchart is as shown in Figure 5 below. Once a time is set, the relay switches on and the electric cooker starts working until the time countdown runs down when the electric cooker is turned off.

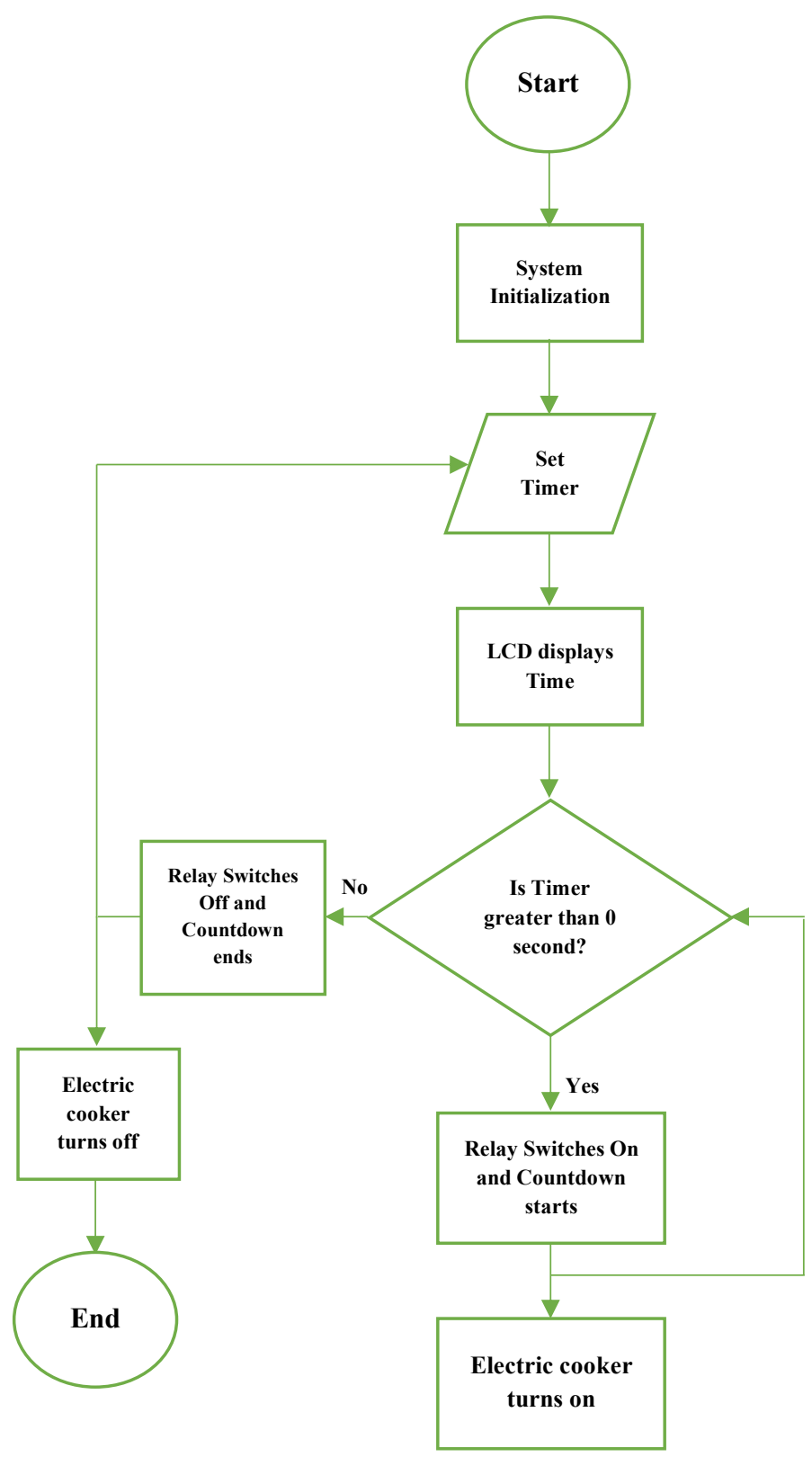

Figure 5. System Flowchart

\section{RESULTS AND DISCUSSION}

With the aid of a proper simulation in accordance to the above stated circuit diagram a functioning timer system is designed and implemented to an electric cooker in accordance to the project aim to control and monitor the usage of the cooker to minimize energy consumption and unnecessary accidents. Fig. 6a shows the timer system running a countdown while the electric cooker is running while Fig. $6 \mathrm{~b}$ displays a time up message to signify the end of the set period and automatically switches off the electric cooker.

Each subsystem was simulated and thereafter implemented as modules and tested to meet the set objectives. Finally, all the modules were integrated into a single low-cost timer system which regulates and control the time of operation to mitigate energy wastage. 


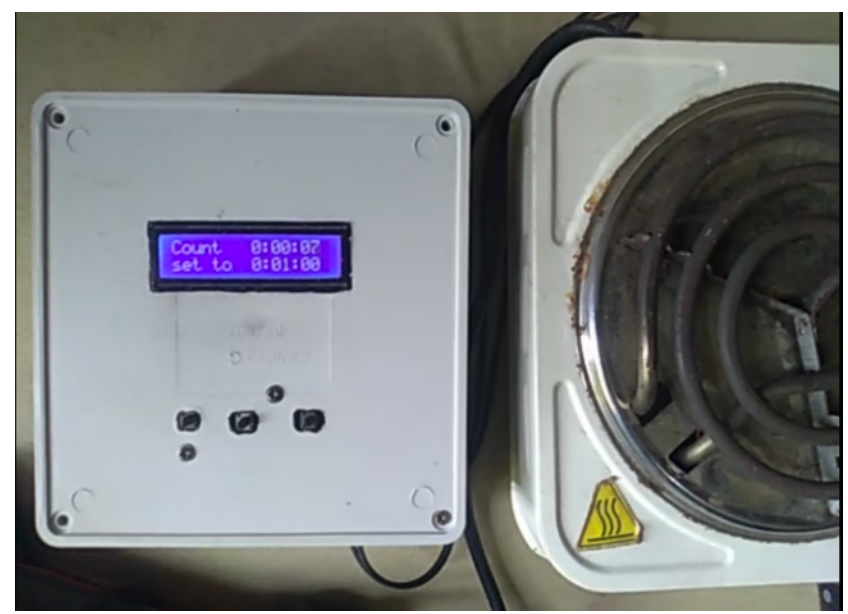

(a)

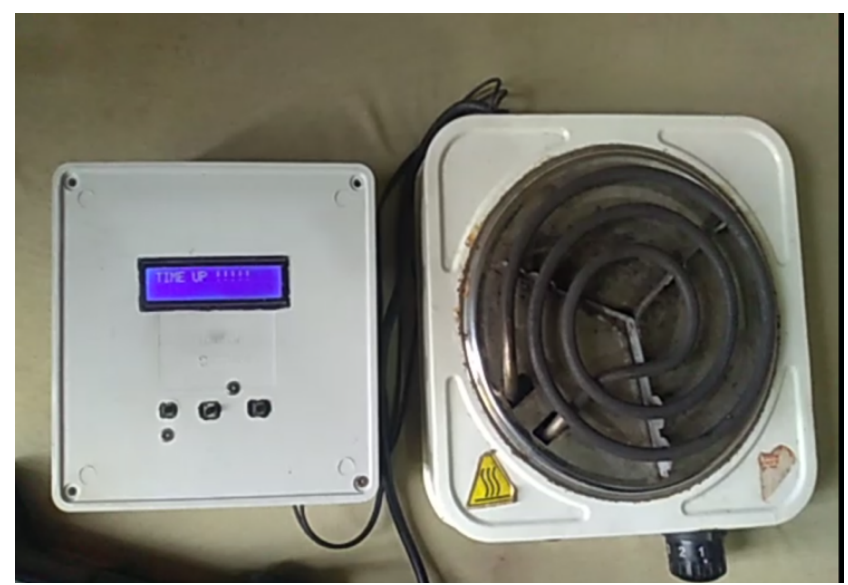

(b)

Fig. 6(a). Timer system running a countdown; (b). Timer system displaying "Time Up" message when the timer runs out.

\section{CONCLUSIONS}

The main motivation of this system is to develop and implement a simple and inexpensive timer for an electric cooker. This project contributes to the effective use of a microcontroller for automation and convenient operation of devices or appliances in this ever progressing, technological world. This has also led to energy saving as it stops energy wastage. This project also provides concepts on how to further improve consumer product or appliances to better suit the demand or desire of the user in terms of convenience and safety. Several tests carried out shows that this system is reliable.

\section{REFERENCES}

[1] K. Nikhil, "Design and Construction of an IOT based Intelligent Home using Smart Devices," International Journal of Innovative Research in Electrical Electronics and Instrumentation Engineering, vol. 4, no. 6, pp. 1209012097, 2016.

[2] M. Shahzamal, M. Haque, H. Nasrul, M. Anzan-Uz-Zaman, S. Rana, M. Hoq, F. Akter, H. Farhana, H. Mahmudul, "Design and Development of Microcontroller Based Programmable Timer for Supply Control," Institute of
Electronics, Atomic Energy Research Establishment, Dhaka, 2013.

[3] A. Oke, O. Olaniyi, O. Arulogun, O. Olaniyan, "Development of a Microcontroller-Controlled Security Door System," Pacific Journal of Science and Technology, vol. 10, no. 2, pp. 398-403, 2009.

[4] M. Effendi, Z. Shayfull, M. Saad, "Design and Implementation of an Alarm Reminder Locking Security System," International Journal of Electronics and Computer Science Engineering, vol. 6, no. 5, pp. 465-472, 2014.

[5] H. Ibrahim, A. Mohammed, I. Aliyu, "Design and Implementation of an Arduino Based Light Dependent Alarm System," Arid Zone Journal of Engineering, Technology \& Environment, vol. 15, no. 2, pp. 259-267, 2019.

[6] S. Htet, Z. Tun, "Design and Implementation of Microcontroller Based Universal Timer for Home Appliances," International Journal of Scientific Engineering and Technology Research, vol. 3, no. 6, pp. 876-882, 2014.

[7] S. Gunputh, A. Murdan, V. Oree, "Design and Implementation of a Low-Cost Arduino-Based Smart Home System," in 9th IEEE Conference on Communication Software and Networks, 2017.

[8] R. Kaler, A Textbook of Microprocessors and Microcontrollers, I K International Publishing House, 2011. 